\title{
Peripheral melatonin mediates neural stimulation of duodenal mucosal bicarbonate secretion
}

\author{
Markus Sjöblom, Gunilla Jedstedt, and Gunnar Flemström \\ Department of Physiology, Uppsala University, Uppsala, Sweden \\ Address correspondence to: Gunnar Flemström, Department of Physiology, \\ Uppsala University, Biomedical Center, PO Box 572, SE-751 23 Uppsala, Sweden. \\ Phone: 46-18-471-43-26; Fax: 46-18-471-49-38; E-mail: Gunnar.Flemstrom@Fysiologi.uu.se.
}

Received for publication April 16, 2001, and accepted in revised form July 20, 2001.

\begin{abstract}
Melatonin is released from intestinal enterochromaffin cells and from the pineal gland, but its role in gastrointestinal function is largely unknown. Our aim was to study the involvement of intestinal and central nervous melatonin in the neurohumoral control of the duodenal mucosa-protective bicarbonate secretion. Working in anesthetized rats, we cannulated a $12-\mathrm{mm}$ segment of duodenum with an intact blood supply and titrated the local bicarbonate secretion with $\mathrm{pH}$-stat. Melatonin and receptor ligands were supplied to the duodenum by close intra-arterial infusion. Even at low doses, melatonin and the full agonist 2-iodo- $N$-butanoyl-5-methoxytryptamine increased duodenal bicarbonate secretion. Responses were inhibited by the predominantly $\mathrm{MT}_{2}$-selective antagonist luzindole but not by prazosin, acting at $\mathrm{MT}_{3}$ receptors. Also, luzindole almost abolished the marked rise in secretion induced by intracerebroventricular infusion of the adrenoceptor agonist phenylephrine. This response was also abolished by sublaryngeal ligation of all nerves around the carotid arteries. However, it was insensitive to truncal vagotomy alone or sympathectomy alone and was unaffected by removal of either the pineal gland or pituitary gland. Thus, melatonin stimulates duodenal bicarbonate secretion via action at enterocyte $\mathrm{MT}_{2}$-receptors and mediates neural stimulation of the secretion.
\end{abstract}

J. Clin. Invest. 108:625-633 (2001). DOI:10.1172/JCI200113052.

\section{Introduction}

Circadian rhythms in pain and discomfort are frequently observed in duodenal ulcer and other gastrointestinal diseases. Knowledge about the neurohumoral mediation of these variations may provide interesting information about intestinal pathophysiology and provide clues to future therapy, but it has been little studied. Duodenal enterocytes transport $\mathrm{HCO}_{3}{ }^{-}$to the lumen, and this alkaline secretion is currently accepted as an important mechanism in duodenal protection $(1,2)$. $\mathrm{HCO}_{3}{ }^{-}$entering the continuous layer of viscoelastic mucus gel on top of the epithelial surface maintains $\mathrm{pH}$ in its cell-facing portion at neutrality in spite of high acidities ( $\mathrm{pH} 1.0-2.0)$ in the duodenal luminal bulk solution $(3,4)$. The secretion is inhibited by nonsteroidal anti-inflammatory drugs and by sympathetic $\alpha_{2}$-adrenoreceptor mediator stimuli and in Helicobacter pylori-infected patients with acute duodenal ulcer disease $(1,2)$.

The protective alkaline secretion is under central as well as local intestinal nervous influence. Intracerebroventricular infusion of the $\alpha_{1}$-selective adrenoceptor agonist phenylephrine causes marked stimulation of duodenal $\mathrm{HCO}_{3}{ }^{-}$secretion in the rat (5). This rise in secretion is inhibited by the ganglion blocking agent hexamethonium and by central nervous (but not by intravenous) administration of the adrenoceptor antagonist prazosin. Centrally elicited stimulation of the secretion has also been observed with some neu- ropeptides, including thyrotropin-releasing hormone (TRH), corticotropin-releasing hormone (CRH), and bombesin $(1,6,7,8)$, as well as with some benzodiazepines (9). Other stimuli of secretion are elicited within the mucosa, and the presence of acid in the duodenal lumen is a main stimulant. The pathways of mediating the response to acid have been reported to involve vasoactive intestinal polypeptide (VIP), acetylcholine, and some other transmitters released from the enteric nervous system $(1,2)$, as well as prostaglandins released from the mucosal cells (10).

The aim of the present study was to examine the influence of melatonin and hormones released from the pituitary gland on duodenal mucosal $\mathrm{HCO}_{3}$ secretion. The neurohormone melatonin is synthesized and released from the pineal gland in a circadian fashion and exerts its action within the central nervous system as well as in peripheral tissues, and melatonin has been implicated in biologic rhythms. Three G protein-coupled melatonin receptor subtypes are reported; the mammalian $\mathrm{MT}_{1}$ and $\mathrm{MT}_{2}$ subtypes, but not yet the $\mathrm{MT}_{3}$ subtype, have been cloned $(11,12)$. One proposed central nervous action of melatonin is induction of changes in the cyclic motility pattern in the rat small intestine by modulation of brain expression of cholecystokinin (13). Previous studies in fasting rats demonstrated circadian rhythms in gastric protective secretions of $\mathrm{HCO}_{3}{ }^{-}$and mucus (14). The duodenal secretion has not been studied in this aspect. 
Melatonin is also present in the enterochromaffin cells of the intestinal mucosa (15), and some studies suggest that nutrients in the lumen influences the intestinal mucosal production of melatonin. Melatonin receptors are reported to be distributed throughout the gastrointestinal tract, but effects of melatonin on intestinal secretion and protection have not been evaluated. The highest concentration of 2-iodomelatonin binding sites in the rat is located in the villi of the small intestine (16). In the duodenum, melatonin has also been localized (immunohistologically) in the areas of Lieberkühn's crypts and Brunner's glands (17).

In view of the central nervous as well as peripheral synthesis and actions of melatonin, melatonin and receptor ligands were administered intra-arterially to the duodenum, thus minimizing any central nervous action of the compounds in these experiments. The effects of central nervous melatonin were studied by intracerebroventricular administration of melatonin and by use of pineal glandectomized animals. The possible effects of hormones released from the pituitary gland were studied by use of pituitary glandectomized animals and by parenteral infusion of some of these hormones in intact animals.

\section{Methods}

This study was approved by the Uppsala University Ethical Committee for Experiments with Animals. Male outbred Sprague-Dawley rats (190-260 g; Møllegaard Breeding Center, Ejby, Denmark) or $\mathrm{F}_{1}$-hybrids of Lewis x Dark Agouti rats (200-260 g; Animal Department, Biomedical Center, Uppsala, Sweden) were placed in a conditioning unit under standardized temperature and light conditions $\left(21-22^{\circ} \mathrm{C}, 12\right.$-hour lightdark cycle) for at least 4 days after purchase. The rats were kept in cages in groups of two or more and had access to tap water and pelleted food (Ewos, Södertälje, Sweden) ad libitum.

Animal preparation. Animals were deprived of food for 20-24 hours before the experiments, but had free access to drinking water. Experiments were started by anesthetizing the animal in the morning at approximately 0900 hours with $120 \mathrm{mg} / \mathrm{kg}$ body weight of 5-ethyl-5(1'-methyl-propyl)-2-thiobarbiturate (Inactin; Research Biochemicals International, Natick, Massachusetts, USA) intraperitoneally. Anesthesia was performed within the Animal Department by the person who had previously handled the animals. Subsequently, the rats were tracheotomized with a tracheal tube to facilitate respiration, and body temperature was maintained at $37-38^{\circ} \mathrm{C}$ throughout experiments by a heating pad controlled by a rectal thermistor probe. The surgical and experimental procedures have been described previously (6). A brief summary is given, and some modifications including close intra-arterial infusion to the duodenum are described here. A femoral artery and vein were catheterized with PE-50 polyethylene catheters (Intramedic, Becton-Dickinson, Franklin Lakes, New Jersey, USA). For continuous recordings of systemic arterial blood pressure, the arterial catheter containing $20 \mathrm{IU} / \mathrm{ml}$ of heparin isotonic saline was connected to a transducer operating a PowerLab system (AD Instruments, Hastings, United Kingdom). The vein was used for injection of some of the drugs and for continuous infusion of Ringer's solution $\left(145 \mathrm{mmol} / \mathrm{l} \mathrm{Na}^{+}, 124\right.$ $\mathrm{mmol} / 1 \mathrm{Cl}^{-}, 2.5 \mathrm{mmol} / 1 \mathrm{~K}^{+}, 0.75 \mathrm{mmol} / \mathrm{l} \mathrm{Ca}^{2+}$ and 25 $\mathrm{mmol} / \mathrm{l} \mathrm{HCO}_{3}{ }^{-}$) at a rate of $1.0 \mathrm{ml} / \mathrm{h}$. The latter was made to compensate for fluid loss and to avoid acidbase changes during the experiments. Blood acid-base balance was controlled (Compact 3, AVL, Graz, Austria) in $40 \mu \mathrm{l}$ arterial blood samples taken at the start and end of experiments. Values of blood $\mathrm{pH}$ (all experiments included) were 7.28-7.45, and changes in base excess were within $\pm 3 \mathrm{mmol} / \mathrm{l}$. The duodenal transmucosal electrical potential difference (PD) was measured in some experiments and recorded between the duodenal mucosa and posterior vena cava with a high-input impedance voltmeter via matched calomel half-cells. The half-cells were connected to the animal by means of agar bridges $(2 \mathrm{M} \mathrm{KCl})$ with their distal ends located in the luminal solution and the posterior vena cava, respectively. All nerves around the carotid arteries (including vagal trunks and sympathetic chain) were ligated and cut at the sublaryngeal level in some experiments as described previously (18). The common carotid arteries were identified, and the surrounding nerves were dissected free from the arteries under light microscopy and cut. In another series of experiments, the vagal trunks (alone) were left.

The abdomen was opened by a midline incision, and the gastric pylorus was ligated with a suture. To avoid bile and pancreatic secretion to enter the intestine, the common bile duct was always catheterized close to its entrance to the duodenum with a PE-10 polyethylene tubing. For measurement of duodenal mucosal $\mathrm{HCO}_{3}$ secretion, a $12-\mathrm{mm}$ segment of duodenum with its blood supply intact, starting $10-12 \mathrm{~mm}$ distal to the pylorus and thus devoid of Brunner's glands, was cannulated in situ between two glass tubes connected to a reservoir. Fluid ( $10 \mathrm{ml}$ of $154 \mathrm{mM} \mathrm{NaCl})$, maintained at $37^{\circ} \mathrm{C}$ by a water jacket, was rapidly circulated by a gas lift of $100 \%$ oxygen. $\mathrm{HCO}_{3}{ }^{-}$secretion into the luminal perfusate was continuously titrated at $\mathrm{pH} 7.4$ with $50 \mathrm{mM} \mathrm{HCl}$ under automatic control of a $\mathrm{pH}$-stat system (Radiometer, Copenhagen, Denmark). After completion of the operative setup, the abdomen was closed with sutures, and the animal was left undisturbed for 1 hour for stabilization of cardiovascular, respiratory, and gastrointestinal functions.

Intra-arterial and intracerebroventricular infusions. To study effects elicited in the duodenal segment and to minimize possible central nervous actions, compounds were administered to the duodenum by close intra-arterial infusion. The hepatic artery was cannulated, tied 3 to $4 \mathrm{~mm}$ proximal to its entrance into the liver, and perfused in the retrograde direction at $17 \mu \mathrm{l} / \mathrm{min}$. This perfusion results in distribution of the perfusate mainly to the duodenum (via the cranial pancreatico-duodenal 
artery) and pancreas. The distribution was checked visually at the start of experiments by intra-arterial injection of a small amount $(\sim 0.1 \mathrm{ml})$ of a marker dye (Evans Blue; $2 \%$ solution in saline).

Intracerebroventricular infusions were made to study duodenal secretory stimulation elicited in the central nervous system. A metal cannula was inserted into the right lateral cerebral ventricle by using a stereotaxic instrument (Model 900; Kopf Instruments, Tujunga, California, USA). A skin incision was made over the right parietal bone, and a $1-\mathrm{mm}$ hole was drilled through the bone, $0.8 \mathrm{~mm}$ posterior to the bregma and $1.5 \mathrm{~mm}$ lateral to the midsagittal suture. A stainless steel cannula was inserted stereotactically and cemented to the skull with cement (Fuji type II; GC Corp., Tokyo, Japan). Artificial cerebrospinal fluid (151.5 mM $\mathrm{Na}^{+}, 3.0 \mathrm{mM} \mathrm{K}^{+}, 1.2 \mathrm{mM} \mathrm{Ca}^{2+}, 0.8 \mathrm{mM} \mathrm{Mg}^{2+}, 132.8 \mathrm{mM}$ $\mathrm{Cl}^{-}, 25 \mathrm{mM} \mathrm{HCO}_{3}{ }^{-}$, and $0.5 \mathrm{mM}$ phosphate [pH 7.4]) was infused through this cannula at a rate of $30 \mu \mathrm{l} / \mathrm{h}$. All agents infused intracerebroventricularly had been dissolved in artificial cerebrospinal fluid. The location of the end of the cannula within the intracerebroventricular space was tested at the end of most experiments by adding Evans blue solution to infusate, followed by dissection of the brain.

Pineal glandectomy. We modified a method described by Hoffman and Reiter (19). Sprague-Dawley rats were anesthetized by intraperitoneal injection $(0.27 \mathrm{ml} / \mathrm{kg}$ body weight) of a solution (Hypnorm; Janssen-Cilag, Bersee, Belgium) containing $0.315 \mathrm{mg} / \mathrm{ml}$ fentanyl, 10 $\mathrm{mg} / \mathrm{ml}$ fluanisone, and $5 \mathrm{mg} / \mathrm{ml}$ midazolam, which induced surgical anesthesia for about 30 minutes. Using the stereotaxic instrument, the head of the rat was fixed and the scalp was cut anterio-posteriorly along the midline. The skin flaps were reflected, and the temporal and occipital muscle masses were scraped free. Three lines were cut with a dental drill equipped with a fissure bar; the bone flap was raised; and the dura mater was cut with a sharp needle. A forceps was put beneath the superior sagittal sinus, and the pineal gland (white and $0.5-1.0 \mathrm{~mm}$ in diameter) was removed. Experiments on the duodenum were not performed until at least 1 week after pineal glandectomy and were performed as described above.

Pituitary glandectomy. Pituitary glandectomy was performed at Møllegaard Breeding Center by personnel with routine experience of this operation. The pituitary gland in male Sprague-Dawley rats (190-230 g) was removed by suction with a syringe through the ear. The animals were observed during 1 week after the operation, and absence of gain in weight (indicating lack of growth hormone incretion) was used to confirm the removal of the pituitary gland. The animals were then transported to Uppsala together with nonoperated animals of the same breed for control experiments. To maintain body acid-base balance, the rats were always supplied with drinking water adjusted to $\mathrm{pH} 3$ with $\mathrm{HCl}$, and 24 hours before experiments, $0.5 \mathrm{mg} / \mathrm{kg}$ dexamethasone (Decadron; Merck Sharp \& Dohme, Haarlem, The
Netherlands) was injected intramuscularly to compensate for the loss of endogenous glucocorticosteroids.

Melatonin analyses. Arterial blood samples (0.7-1.0 $\mathrm{ml}$ ) were obtained from the rat tail artery (a) before pineal glandectomy, (b) 1 day before the experiment in animals to be exposed to intracerebroventricular infusion of either phenylephrine or vehicle, and (c) 3 hours after the start of these experiments from the femoral artery. All blood samples were taken between 1100 and 1500 hours. The blood samples were left for $30 \mathrm{~min}-$ utes at room temperature to coagulate and were then centrifuged at $5,000 \mathrm{~g}$ in $4^{\circ} \mathrm{C}$ for 7 minutes. The serum was then stored at $-20^{\circ} \mathrm{C}$ until analysis (Nova Medical $\mathrm{AB}$, Skövde, Sweden) using an ELISA assay (Bühlmann Laboratories, Allschwil, Switzerland). The detection limit of the assay is $0.05 \mathrm{pmol} / \mathrm{ml}$. The intra- and interassay coefficients were below $6.6 \%$.

Experimental protocols. After anesthesia and operative procedures, the animals were allowed to stabilize for 1 hour. Basal rate of $\mathrm{HCO}_{3}{ }^{-}$secretion was then titrated for 30-40 minutes. Test compounds were administered, and the secretion was continuously measured for another 140-200 minutes. At the end of most experiments, the responsiveness of the preparation was tested by administering $20 \mu \mathrm{mol} / \mathrm{l}$ prostaglandin $\mathrm{E}_{2}\left(\mathrm{PGE}_{2}\right)$ intraluminally. The prostaglandin was added as a small amount from an ethanol stock solution stored at $-20^{\circ} \mathrm{C}$.

A series of control experiments were run as follows. Basal $\mathrm{HCO}_{3}{ }^{-}$secretion in $\mathrm{F}_{1}$-hybrids of Lewis x Dark Agouti rats bred at the Uppsala Biomedical Center and in such rats exposed to intra-arterial infusion of saline alone was measured for 210 minutes. In Sprague-Dawley rats, basal $\mathrm{HCO}_{3}{ }^{-}$secretion was measured during a period of 230 minutes. For comparison with effects of intracerebroventricular infusions in such animals, basal secretion was measured during a 30-minute period followed by a 170-minute period with infusion of artificial cerebrospinal fluid alone. Similar controls of basal $\mathrm{HCO}_{3}{ }^{-}$secretion and of secretion during intracerebroventricular infusion were performed in the pituitary glandectomized (Møllegaard) or pineal glandectomized Sprague-Dawley rats.

Data analyses. Descriptive statistics are expressed as means $\pm \mathrm{SE}$, with the number of experiments given in parentheses. Rates of alkaline secretion by the duodenum are expressed as microequivalents of base $\left(\mathrm{HCO}_{3}{ }^{-}\right)$ per centimeter of intestine per hour $\left(\mu \mathrm{Eq} \cdot \mathrm{cm}^{-1} \cdot \mathrm{h}^{-1}\right)$. The secretion and mean arterial blood pressure (MAP) were recorded continuously and registered at 10minute intervals. The statistical significance of data was tested by repeated-measures ANOVA. To test the difference within a group, a one-factor repeated measure ANOVA was used followed by Fisher's PLSD post hoc test. Between groups, the results of $\mathrm{HCO}_{3}{ }^{-}$secretion with drug administration were compared with the secretory rates obtained with control animals infused with vehicle alone or with other drug treatments. For this comparison, a two-factor repeated measures ANOVA followed by a one-way ANOVA at each time 


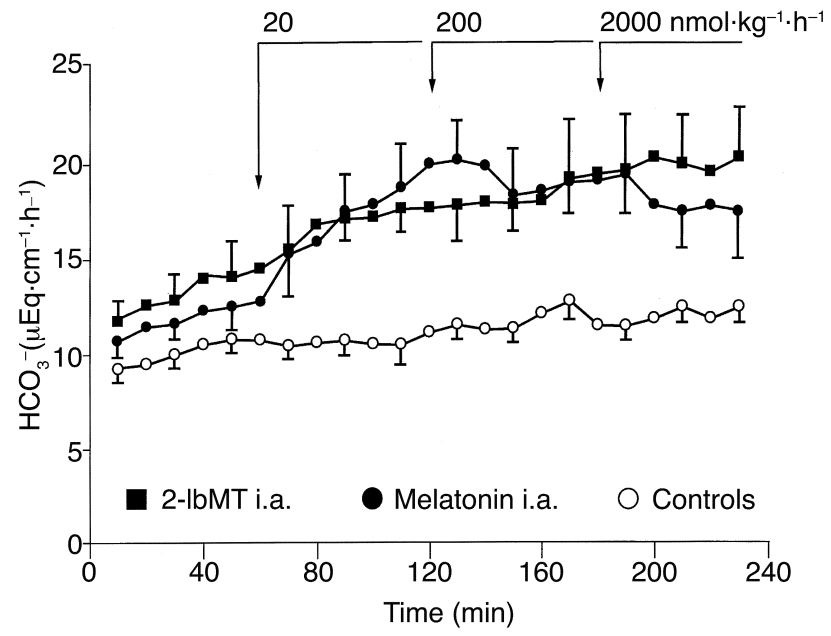

Figure 1

Melatonin and the $\mathrm{MT}_{1} / \mathrm{MT}_{2}$ receptor agonist 2-IbMT were administered to the duodenum by close intra-arterial (i.a.) infusion. Control animals were infused with vehicle (isotonic saline) alone. Means $\pm \mathrm{SE}$ of $\mathrm{HCO}_{3}{ }^{-}$secretion are shown $(n=6$ in all groups). No changes in MAP occurred in these experiments (data not shown).

point was used. If the ANOVA was significant at a given time point, a Fisher's PLSD post hoc analyses was used. All statistical analyses were performed on an IBM-compatible computer using StatView 5.0 software (SAS Institute Inc., Cary, North Carolina, USA.). $P$ values of $<0.05$ were considered significant.

Chemicals and drugs. L-Phenylephrine hydrochloride, $\mathrm{PGE}_{2}$, and $\gamma$-melanocyte-stimulating hormone (MSH) were purchased from Sigma Chemical Co. (St. Louis, Missouri, USA). Melatonin and 5-ethyl-5-(1'-methylpropyl)-2-thiobarbiturate (Inactin) were from Research Biochemicals International. The more short-acting anesthetic Hypnorm was used for pineal glandectomy and obtained from Janssen-Cilag. Prazosin hydrochloride, the melatonin receptor agonist 2-iodo- $\mathrm{N}$-butanoyl-5methoxytryptamine (2-IbMT), and antagonists luzindole and 4-phenyl-2-propionamidotetraline (4-P-PDOT) were obtained from Tocris Cookson Ltd. (Avonmouth, Bristol, United Kingdom). The pituitary peptides CRH and rat adrenocorticotropic hormone (ACTH) were from Peninsula Laboratories Europe Ltd. (Merseyside, United Kingdom). Pituitary glandectomized rats were given the glucocorticoid dexamethasone Decadron.

\section{Results}

The duodenal segment spontaneously secreted $\mathrm{HCO}_{3}{ }^{-}$ at a steady basal rate in all groups tested, and this was not influenced by either intra-arterial (isotonic saline) or intracerebroventricular (artificial cerebrospinal fluid) infusions of vehicle (see Figure 1 and Figure 3). Similarly, neither of the infusions of vehicle affected the MAP. Stimulation of duodenal $\mathrm{HCO}_{3}{ }^{-}$secretion by exogenous melatonin and receptor agonists. Close intra-arterial infusion of melatonin $\left(20,200\right.$, and $\left.2,000 \mathrm{nmol} \cdot \mathrm{kg}^{-1} \cdot \mathrm{h}^{-1}\right)$ to the duodenum significantly increased mucosal
$\mathrm{HCO}_{3}{ }^{-}$secretion (Figure 1) but did not affect the transmucosal PD ( $P>0.05$; data not shown). This secretion started to increase 20 minutes after the start of infusion of the lowest dose tested $\left(20 \mathrm{nmol} \cdot \mathrm{kg}^{-1}\right.$. $\left.\mathrm{h}^{-1}\right)$ and peaked after 60 minutes. The rise was from $10.6 \pm 1.1$ to $20.0 \pm 2.3 \mu \mathrm{Eq} \cdot \mathrm{cm}^{-1} \cdot \mathrm{h}^{-1}(P<0.05)$; secretion did not increase further with the higher doses. In contrast, $\mathrm{HCO}_{3}{ }^{-}$secretion tended to decline with 200 and 2,000 $\mathrm{nmol} \cdot \mathrm{kg}^{-1} \cdot \mathrm{h}^{-1}$, but was always significantly greater $(P<0.05)$ than the basal secretion. $\mathrm{PGE}_{2}$ (20 $\mu \mathrm{M}$ luminally) added at the end of experiments as a test of the viability of the preparation (data not shown) increased the $\mathrm{HCO}_{3}{ }^{-}$secretion and also caused a rise in transmucosal PD (from $1.2 \pm 0.6$ to 2.4 $\pm 0.6 \mathrm{mV}$, lumen negative). As found with melatonin, close intra-arterial infusion of the receptor agonist 2iodo- $N$-butanoyl-5-methoxytryptamine (2-IbMT) significantly stimulated $(P<0.05)$ the $\mathrm{HCO}_{3}{ }^{-}$secretion (Figure 1). Neither melatonin (Figure 2) nor 2-IbMT (data not shown) affected the MAP.

Intravenous infusion of consecutively increasing doses of melatonin $\left(40,200\right.$, and $800 \mathrm{nmol} \cdot \mathrm{kg}^{-1} \cdot \mathrm{h}^{-1}$ for 40 minutes with each dose) was tested in some experiments for comparison ( $n=6$; data not shown). Only the highest of these dose tested $\left(800 \mathrm{nmol} \cdot \mathrm{kg}^{-1}\right.$. $\left.\mathrm{h}^{-1}\right)$ increased the $\mathrm{HCO}_{3}{ }^{-}$secretion $(P<0.05$, compared with vehicle alone). Close intra-arterial infusion of melatonin to the duodenum is thus significantly more effective than intravenous administration of the compound. As found with intra-arterial melatonin, intravenous melatonin did not affect the transmucosal PD.

The effects of central nervous administration of melatonin were tested by intracerebroventricular infusion ( $n=6$; data not shown). Infusion of $20 \mathrm{nmol} \cdot \mathrm{kg}^{-1} \cdot \mathrm{h}^{-1}$ of melatonin for 110 minutes into a lateral brain ventricle affected neither the duodenal $\mathrm{HCO}_{3}{ }^{-}$secretion nor the MAP.

Effects of melatonin receptor antagonists. The melatonin $\mathrm{MT}_{1} / \mathrm{MT}_{2}$ receptor antagonists luzindole and 4-PPDOT, and prazosin (which is an antagonist at $\mathrm{MT}_{3}$ receptors), were used. First, the effects on spontaneous (basal) $\mathrm{HCO}_{3}{ }^{-}$secretion were examined. Luzindole infused close intra-arterially to the duodenal segment at the consecutively increasing doses of 20,200, and 2,000 $\mathrm{nmol} \cdot \mathrm{kg}^{-1} \cdot \mathrm{h}^{-1}$ (Figure 2), or 4-P-PDOT (20 and 200 $\mathrm{nmol} \cdot \mathrm{kg}^{-1} \cdot \mathrm{h}^{-1}, n=6$; data not shown) did not affect basal alkaline secretion or MAP. Similarly, luzindole did not affect the rise in $\mathrm{HCO}_{3}{ }^{-}$secretion in response to 20 $\mu \mathrm{M} \mathrm{PGE}_{2}$ (added luminally at the end of experiments; data not shown). Bolus injection of a higher dose of luzindole $\left(6,000 \mathrm{nmol} \cdot \mathrm{kg}^{-1} ; n=7\right.$; data not shown), however, caused an immediate and transient rise $(-25 \%$; $P<0.05)$ in $\mathrm{HCO}_{3}{ }^{-}$secretion, suggesting some agonist activity. Neither the highest $\left(6,000 \mathrm{nmol} \cdot \mathrm{kg}^{-1}\right)$ nor lower doses of luzindole significantly changed MAP.

The subtype selective antagonists were then studied to characterize the response to exogenous melatonin. Pretreatment with luzindole as a bolus dose not affecting basal $\mathrm{HCO}_{3}{ }^{-}$secretion $(600 \mathrm{nmol} / \mathrm{kg})$ was used to block 


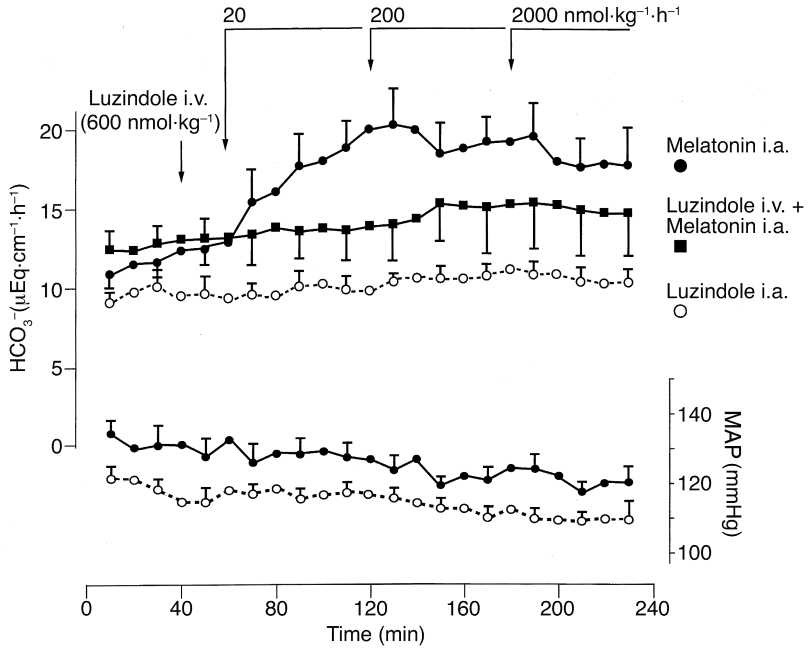

Figure 2

Close intra-arterial infusion of the $\mathrm{MT}_{1} / \mathrm{MT}_{2}$ antagonist luzindole at doses indicated did not affect basal $\mathrm{HCO}_{3}{ }^{-}$secretion $(n=6)$. Pretreatment with luzindole $(600 \mathrm{nmol} / \mathrm{kg}$ by intravenous [i.v.] bolus injection), however, significantly inhibited the rise in duodenal mucosal $\mathrm{HCO}_{3}{ }^{-}$secretion induced by intra-arterial melatonin. Effects of intra-arterial melatonin alone are shown for comparison. Means $\pm \mathrm{SE}$ of $\mathrm{HCO}_{3}{ }^{-}$secretion are shown ( $n=6$ in all groups). No changes in MAP were observed in these experiments.

$\mathrm{MT}_{2}$ receptors. Intravenous bolus injection of this dose of luzindole 20 minutes before the start of melatonin infusion prevented the $\mathrm{HCO}_{3}^{-}$response by melatonin (Figure 2). Melatonin $\mathrm{MT}_{3}$-receptor blockade was attained by pretreatment with prazosin, an antagonist at these receptors (as well as at $\alpha_{1}$-adrenoceptors). Intravenous bolus injection of prazosin $(1.0 \mu \mathrm{mol} / \mathrm{kg})$ caused a sustained and profound decline in the MAP, from $127 \pm 3$ to $79 \pm 3 \mathrm{mmHg}(n=6)$. However, close intra-arterial melatonin $\left(2,000 \mathrm{nmol} \cdot \mathrm{kg}^{-1} \cdot \mathrm{h}^{-1}\right.$, started 60 minutes after prazosin) caused a significant increase in $\mathrm{HCO}_{3}{ }^{-}$ secretion $(P<0.05)$ in spite of the low blood pressure.

Intracerebroventricular phenylephrine induced duodenal $\mathrm{HCO}_{3}{ }^{-}$secretion. Intracerebroventricular infusion of the $\alpha_{1}$-adrenoceptor agonist phenylephrine markedly stimulates duodenal alkaline secretion, but the neurohumoral pathways mediating this secretory response have not been elucidated (5). Effects of intracerebroventricular phenylephrine alone were confirmed in a first series of experiments (Figure 3). Infusion of phenylephrine at a rate of $12.2 \mu \mathrm{mol} \cdot \mathrm{kg}^{-1} \cdot \mathrm{h}^{-1}$ increased the $\mathrm{HCO}_{3}{ }^{-}$secretion from $4.5 \pm 0.5$ to $19 \pm 2.1 \mu \mathrm{Eq} \cdot \mathrm{cm}^{-1} \cdot \mathrm{h}^{-1}(P<0.05)$. The increase began 30 minutes after start of the phenylephrine infusion and peaked after 70 minutes. A transient increase in arterial pressure was observed during the first 5 minutes of the intracerebroventricular phenylephrine challenge.

Bilateral cutting of the vagal trunks inhibits the rise in duodenal secretion induced by intracerebroventricular infusion of TRH and some other agents $(6,7,9)$, but the same kind of vagotomy (at the sublaryngeal level) does not affect the response to intracerebroven- tricular phenylephrine (5). Effects of extended pericarotid nervectomies were tested in the present study (Figure 4). Cutting of all nerves around the carotid arteries at the sublaryngeal level, including both the vagal trunks and the sympathetic chains, significantly $(P<0.05)$ inhibited the duodenal secretory response to intracerebroventricular phenylephrine. In contrast, the response was unaffected in animals with the vagal trunks excluded from the extended nervectomy (Figure 4). Thus, sympathectomy alone, like truncal vagotomy alone, is insufficient for inhibition of the response to intracerebroventricular phenylephrine.

Pretreatment with the melatonin antagonist luzindole was tested in another series of experiments. A dose $\left(600 \mathrm{nmol} \cdot \mathrm{kg}^{-1}\right)$ not affecting basal secretion but preventing the stimulation of $\mathrm{HCO}_{3}{ }^{-}$secretion by intraarterial melatonin was chosen. As shown in Figure 3, luzindole also markedly inhibited the duodenal secretory response to intracerebroventricular phenylephrine. The response decreased to only a small and transient increase with a peak 70 minutes after start of phenylephrine infusion. The secretion then decreased to the baseline level recorded at start of experiments.

Pineal glandectomy and intracerebroventricular phenylephrine. The prevention of the intracerebroventricular phenylephrine-induced secretory response by the melatonin receptor ligand luzindole made it interesting to study the response in pineal glandectomized rats. The removal of the pineal gland should remove much of the central nervous (but not the peripheral) production of melatonin. Pineal glandectomized rats

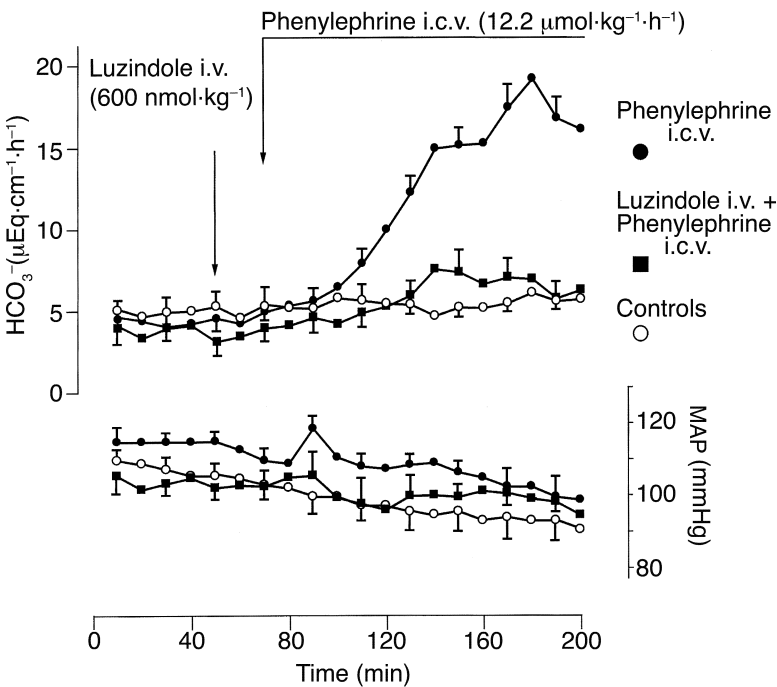

\section{Figure 3}

Intracerebroventricular (i.c.v.) infusion of phenylephrine 12.2 $\mu \mathrm{mol} \cdot \mathrm{kg}^{-1} \cdot \mathrm{h}^{-1}$ increased the $\mathrm{HCO}_{3}{ }^{-}$secretion by the duodenal mucosa. Pretreatment with the melatonin receptor antagonist luzindole $(600 \mathrm{nmol} / \mathrm{kg}$ by intravenous bolus injection) markedly inhibited the duodenal secretory response to intracerebroventricular phenylephrine. Means $\pm \mathrm{SE}$ of $\mathrm{HCO}_{3}{ }^{-}$secretion and MAP in phenylephrine-infused groups and in control animals infused with vehicle (artificial cerebrospinal fluid alone) are shown $(n \geq 6)$. 

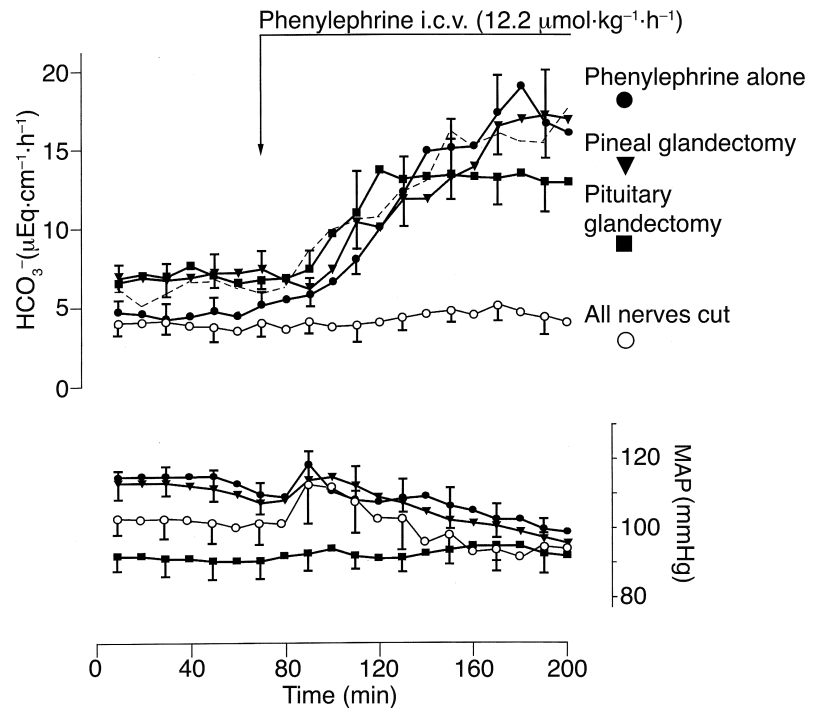

\section{Figure 4}

Neither pineal glandectomy nor pituitary glandectomy inhibited the duodenal secretory response to intracerebroventricular phenylephrine $\left(12.2 \mu \mathrm{mol} \cdot \mathrm{kg}^{-1} \cdot \mathrm{h}^{-1}\right)$. Removal of all nerves passing along the carotid arteries (including sympathetic nerves) significantly inhibited this duodenal response to intracerebroventricular phenylephrine. In contrast, the response remained in animals with the vagal trunks excluded from the pericarotid nervectomy (dashed line). Means $\pm \mathrm{SE}$ of $\mathrm{HCO}_{3}{ }^{-}$secretion and MAP ( $n \geq 6$ in all groups). Control animals were not nervectomized and were exposed to intracerebroventricular phenylephrine alone.

had the same rates of spontaneous (basal) duodenal $\mathrm{HCO}_{3}{ }^{-}$secretion $\left(5.8 \pm 1.7 \mu \mathrm{Eq} \cdot \mathrm{cm}^{-1} \cdot \mathrm{h}^{-1} ; n=5\right)$ as intact rats $\left(5.1 \pm 0.6 \mu \mathrm{Eq} \cdot \mathrm{cm}^{-1} \cdot \mathrm{h}^{-1} ; n=6\right)$. Intracerebroventricular phenylephrine induced a threefold increase $(P<0.05)$ in secretion, from $6.6 \pm 1.2$ to $17.3 \pm$ $3.0 \mu \mathrm{Eq} \cdot \mathrm{cm}^{-1} \cdot \mathrm{h}^{-1}$, in the pineal glandectomized rats (Figure 4). As found with the basal secretion, the response to phenylephrine was not significantly different $(P>0.05)$ from that seen in the intact animals.

The concentration of melatonin in arterial blood preceding the pineal glandectomy operation was 0.17 $\pm 0.03 \mathrm{nmol} / \mathrm{l}$. When measured more than 1 week after pineal removal ( 24 hours before the beginning of the duodenal experiment), the concentration was $0.15 \pm 0.01 \mathrm{nmol} / \mathrm{l}$. In both of these groups $(n=12)$, blood samples were taken between 1100 and 1400 hours. In rats exposed to intracerebroventricular phenylephrine, the melatonin concentration was 0.20 $\pm 0.02 \mathrm{nmol} / \mathrm{l}(n=6)$, and in rats given vehicle (artificial spinal fluid) alone, $0.18 \pm 0.02 \mathrm{nmol} / 1(n=6)$. Samples were taken between 1100 and 1500 hours. Neither the difference between pineal gland ectomized and intact animals nor that between phenylephrine- and vehicle alone-infused animals was statistically significant $(P>0.05)$.

Pituitary glandectomy and effects of exogenous pituitary peptides. $\beta$-Endorphin released from the pituitary gland is a mediator in duodenal $\mathrm{HCO}_{3}{ }^{-}$secretion in response to intracerebroventricular CRH (8). It has also been found that the pituitary peptides PACAP-27 and PACAP-38 (administered intravenously) are potent stimuli of the alkaline secretion (20). Thus, it was of interest to study the duodenal $\mathrm{HCO}_{3}{ }^{-}$secretion in pituitary glandectomized animals. Basal $\mathrm{HCO}_{3}{ }^{-}$secretion in these rats $\left(6.2 \pm 0.7 \mu \mathrm{Eq} \cdot \mathrm{cm}^{-1} \cdot \mathrm{h}^{-1} ; n=6\right)$ measured around 20 days after gland removal did not differ from that in intact controls $\left(5.1 \pm 0.6 \mu \mathrm{Eq} \cdot \mathrm{cm}^{-1} \cdot \mathrm{h}^{-1} ; n=6\right)$ from the same breed. The rise in secretion in response to intracerebroventricular phenylephrine infusion $\left(12.2 \mu \mathrm{mol} \cdot \mathrm{kg}^{-1} \cdot \mathrm{h}^{-1}\right)$ was from $6.8 \pm 0.6$ to $13.7 \pm 1.7$ $\mu \mathrm{Eq} \cdot \mathrm{cm}^{-1} \cdot \mathrm{h}^{-1}(P<0.05)$ and not significantly different from that in intact controls.

Pituitary peptides thus seemed unlikely contributors to the response to intracerebroventricular phenylephrine. Effects of exogenous administration of some peptides released with marked day and night rhythms from the pituitary gland were studied in further experiments (Lewis x Dark Agouti rats). A 40-minute control period was followed by intravenous infusion of CRH $\left(10 \mathrm{nmol} \cdot \mathrm{kg}^{-1} \cdot \mathrm{h}^{-1} ; n=6\right)$, ACTH $(2-40$ $\left.\mathrm{nmol} \cdot \mathrm{kg}^{-1} \cdot \mathrm{h}^{-1} ; n=4\right)$ or MSH $\left(2-40 \mathrm{nmol} \cdot \mathrm{kg}^{-1} \cdot \mathrm{h}^{-1}\right.$; $n=6)$ for 120 minutes. Neither of the tested hormones affected duodenal mucosal $\mathrm{HCO}_{3}{ }^{-}$secretion, whereas $\mathrm{PGE}_{2}$, added luminally $(20 \mu \mathrm{mol} / \mathrm{l})$ at the end of experiments, increased the secretion in all animals.

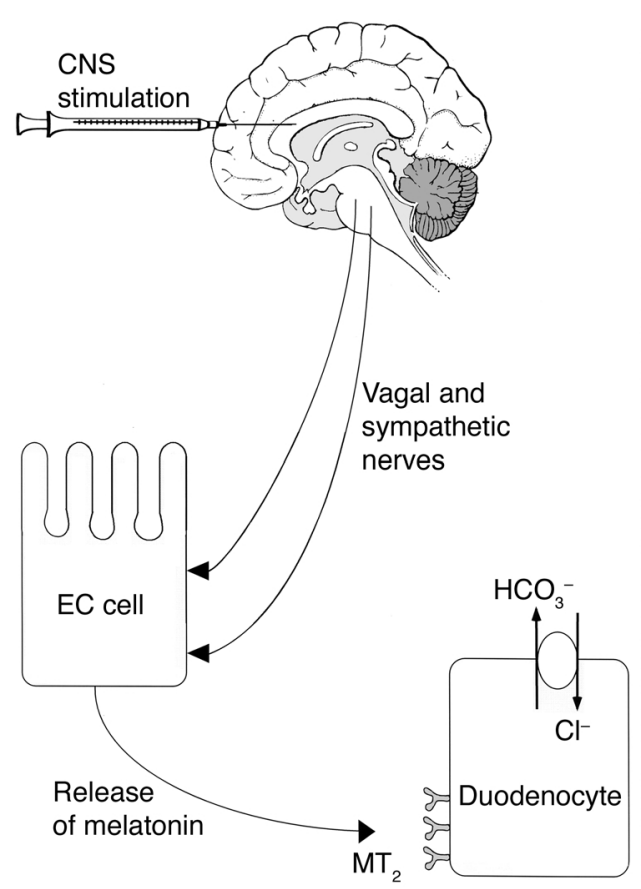

Figure 5

Model illustrating the proposed role of melatonin in control of duodenal mucosal $\mathrm{HCO}_{3}{ }^{-}$secretion. Melatonin released from intestinal enterochromaffin cells stimulates the protective secretion via an action at enterocyte $\mathrm{MT}_{2}$-receptors. Release is initiated by central nervous (intracerebroventricular) administration of adrenoceptor agonist phenylephrine, and neural pathways involve sympathetic as well as vagal components. The absence of significant changes in electrical potential difference suggests activation of electroneutral $\mathrm{Cl}^{-} / \mathrm{HCO}_{3}^{-}$exchange. 


\section{Discussion}

A number of common diseases in humans, including gastroduodenal ulcer and irritable bowel syndrome, are well known for showing circadian rhythms in pain and discomfort. Further, studies in fasting animals have demonstrated that the gastric secretions of $\mathrm{HCO}_{3}{ }^{-}$and mucus, both important in mucosal protection, shows day and night rhythms with peak times different from those of the mucosa-aggressive $\mathrm{H}^{+}$ secretion (14). This phase shift in secretory rhythms may, in theory, result in circadian variations in mucosal vulnerability to acid injury. The incidence of gastroduodenal ulcer reportedly peaks at certain periods of the year (21). Fuller information about circadian rhythms and, in particular, about the neurohumoral pathways from internal clocks to tissues and ion-transporting cells, should provide relevant information about intestinal pathophysiology and may provide clues to future therapy. It should be emphasized that recent studies have shown that internal clock systems are located not only in the central nervous system but also in peripheral tissues, including within the gastrointestinal tract (22). The aim of the present study was to examine the role of the pineal gland neurohormone melatonin and some pituitary gland hormones in the peripheral and central nervous control of the mucosa-protective $\mathrm{HCO}_{3}{ }^{-}$secretion in the duodenum. In humans and other mammals, including rodents, melatonin secretion from the pineal gland peaks at darkness (night), independently of species differences in day or night activity (11). Melatonin is synthesized from tryptophan, with serotonin as an intermediate, and is released from the pineal gland in mammals into the circulation. Being a nonpolar and lipid-soluble indoleamine, melatonin crosses the blood-brain barrier and acts at melatoninspecific receptors in the central nervous system as well as such receptors in peripheral tissues.

Importantly, melatonin is also one of the transmitters produced by the enterochromaffin cells of the intestinal mucosa (15), and the total amount of melatonin in the alimentary tract is considerably higher than that in the central nervous system (23). It should also be noted that the enterochromaffin cells are in close contact with fibers from the autonomic nervous system (24). A physiological role of this source of melatonin has not previously been clarified; nor has any interaction between pineal gland and intestinal mucosal melatonin production. Like the enterochromaffin cell products uroguanylin and guanylin (25) and serotonin, intestinal melatonin may have a role in the reaction of the mucosa to luminal contents. The results of the present study strongly suggest that intestinal sources of melatonin are involved in mediating central nervous influence on duodenal epithelial $\mathrm{HCO}_{3}{ }^{-}$secretion and mucosal protection.

Stimulation of duodenal $\mathrm{HCO}_{3}{ }^{-}$secretion by peripheral melatonin. Melatonin and the full agonist 2-IbMT stimulated mucosal $\mathrm{HCO}_{3}{ }^{-}$secretion when adminis- tered to the duodenum by close intra-arterial infusion, a procedure that should minimize any central nervous actions of the compounds (Figure 1). Considerably higher doses were required for stimulation when the hormone was given intravenously, strongly indicating that the stimulation by melatonin is elicited within the duodenum and not a primary central nervous action mediated to the intestine. Stimulation of the $\mathrm{HCO}_{3}$ secretion by local intestinal melatonin seems also in line with the recent finding that melatonin increases intracellular $\mathrm{Ca}^{2+}$ in isolated duodenal enterocytes (26) and may suggest an action at enterocyte rather than enteric nervous receptors. It should be noted that the doses of melatonin required for stimulation of duodenal $\mathrm{HCO}_{3}{ }^{-}$secretion seem much lower (>100-fold) than those tested in animal models of depressive disease (27) or used in humans for therapy of sleep disturbance or depression (28).

The $\mathrm{MT}_{1} / \mathrm{MT}_{2}$ receptor antagonist luzindole inhibited the rise in secretion induced by melatonin. Studied in other tissues, luzindole shows considerably higher affinity for $\mathrm{MT}_{2}$ than $\mathrm{MT}_{1}$ receptors $(11,12)$. An action mediated via $\mathrm{MT}_{1}$ receptors cannot be excluded but would seem less likely. Evaluation of this possibility would require $\mathrm{MT}_{1}$-selective $\left(\mathrm{MT}_{1}>\mathrm{MT}_{2}\right)$ agonists or antagonists, but such ligands have not yet been described $(11,12)$. Prazosin is an antagonist at melatonin $\mathrm{MT}_{3}$ receptors as well as at $\alpha_{1}$-adrenoceptors. Intravenous bolus injection of the compound caused a sustained decline in MAP (to $<80 \mathrm{mmHg}$ ), most probably reflecting the adrenoceptor activity of prazosin. However, close intra-arterial infusion of melatonin caused a significant increase in $\mathrm{HCO}_{3}$ secretion in spite of the low pressure, strongly suggesting that $\mathrm{MT}_{3}$ receptors do not mediate the melatonin-induced stimulation. Neither luzindole at a dose inhibiting the stimulation by exogenous melatonin, nor another antagonist (4-P-PDOT) affected spontaneous (basal) $\mathrm{HCO}_{3}{ }^{-}$secretion. This suggests an absence of endogenous melatonin on basal secretion. However, the present experiments were performed during daytime when endogenous production of melatonin is low. They do not exclude an increase in protective $\mathrm{HCO}_{3}{ }^{-}$secretion induced by the higher levels of melatonin at night.

Central nervous stimulation of $\mathrm{HCO}_{3}{ }^{-}$secretion. Bilateral cutting of the vagal trunks at the sublaryngeal level inhibits the stimulation of duodenal $(6,7)$ and pancreatic (29) secretion induced by intracerebroventricular infusion of the neuropeptide TRH. Truncal vagotomy alone also abolishes the responses to intracerebroventricular administration of bombesin (6) and intracerebroventricular or intravenous administration of some benzodiazepines (9), but identical vagotomy does not affect the response to intracerebroventricular phenylephrine (5). It was found in the present study that cutting all nerves around the carotid arteries, in contrast to sympathectomy alone and findings after truncal vagotomy, 
markedly inhibits the duodenal secretory response to intracerebroventricular phenylephrine (Figure 4). Differences between truncal vagotomy alone and extended pericarotid nervectomy has been observed before in studies of duodenal distension-secretory interactions (18) and may reflect intercommunications between vagal and sympathetic neural pathways at the cervical level (30) and anatomical mixing between these pathways (31).

Further, the present study demonstrates the melatonin receptor antagonist luzindole is a potent inhibitor of the duodenal secretory response to central nervous (intracerebroventricular) phenylephrine (Figure 3). Melatonin could be a transmitter at the central nervous level as well as at the intestinal level, and luzindole could have an action at either or both levels. Basal $\mathrm{HCO}_{3}{ }^{-}$secretion in pineal glandectomized animals was, however, not significantly lower than that observed in intact control animals, and there was no significant difference between ectomized and nonectomized rats in respect to the secretory response to intracerebroventricular phenylephrine. A tendency of blood melatonin to increase after intracerebroventricular phenylephrine was observed when pineal glandectomized rats were compared with such animals infused intracerebroventricularly with vehicle alone, but this tendency did not attain statistical significance. The combined results strongly suggest that melatonin released from the pineal gland is not the main mediator of the rise in duodenal secretion.

Melatonin released from the pineal gland may, however, be important in the night control of the duodenal secretion and mucosal protection. Recent studies in rats have shown that during the dark phase, compared with daylight phase, the frequency of duodenal and jejunum intestinal migrating motor complexes was increased by $20 \%$ and that this was abolished by the melatonin antagonist S22153 (32). These authors concluded that pineal gland melatonin is involved in the dark-phase physiological control of the pre- and postprandial changes of intestinal motility. Considering release from the duodenal mucosa, the concentrations of melatonin in the present study were measured in samples from the femoral and tail artery. Concentrations in venous blood leaving the duodenum would have been interesting, but adequate samples could not be attained because of the complex distribution of the duodenal venous outflow.

Pituitary glandectomized animals were used to elucidate whether release of hormones from the pituitary gland could contribute to the potent stimulation of duodenal secretion in response to intracerebroventricular phenylephrine. The response to intracerebroventricular phenylephrine was, however, not different from that in nonectomized animals (Figure 4), strongly suggesting that pituitary hormones do not mediate the response. This was further confirmed by the finding that, when infused intravenously, neither $\mathrm{CRH}, \mathrm{ACTH}$, nor $\mathrm{MSH}$ affected the duodenal $\mathrm{HCO}_{3}{ }^{-}$secretion in intact animals.
Melatonin in mucosal protection. Convincing evidence has been provided that $\mathrm{HCO}_{3}{ }^{-}$secreted into the adherent mucus gel layer at the epithelial surface provides the main mechanism for duodenal mucosal protection against $\mathrm{HCl}$ discharged from the stomach (2). Duodenal enterocytes export $\mathrm{HCO}_{3}^{-}$by apical $\mathrm{Cl}^{-} / \mathrm{HCO}_{3}^{-}$ exchange as well as via an anion conductive pathway, likely the cystic fibrosis transmembrane resistance (CFTR). Anion-channel-dependent transport of $\mathrm{HCO}_{3}$ may, as suggested for secretion of anions (predominantly $\mathrm{Cl}^{-}$) by more distal small intestine, be a property of crypt cells, where, also, CFTR is expressed at the greatest levels. The villus apical transporter may, in contrast, involve the (electroneutral) anion exchanger.

The results of the present study demonstrates that melatonin stimulates duodenal mucosal secretion of $\mathrm{HCO}_{3}{ }^{-}$, likely via action at enterocyte $\mathrm{MT}_{2}$-receptors, and that stimulation occurs without significant changes in the transepithelial electrical potential difference. The highest concentration of 2-iodomelatonin binding sites is, as proposed for the electroneutral $\mathrm{HCO}_{3}{ }^{-}$exporter, located in the villi of the rat small intestine (16). The combined data thus suggest that melatonin stimulates the mucosa-protective $\mathrm{HCO}_{3}$ secretion in the most acid-exposed (villus) portion of the duodenal epithelium (Figure 5). Secretion is initiated by stimuli transferred from the central nervous system via neural pathways that likely involve vagal as well as sympathetic components. Further knowledge about the release and protective actions of melatonin and other enterochromaffin cell products would seem of considerable interest.

\section{Acknowledgments}

We thank Olof Nylander and Jon I. Isenberg for valuable discussions and helpful comments. Support was given by the Swedish Medical Research Council (grant 3515).

1. Flemström, G. 1994. Gastric and duodenal mucosal bicarbonate secretion. In Physiology of the gastrointestinal tract. 3rd edition. L.R. Johnson, E.D. Jacobson, J. Christensen, D. Alpers, and J.H. Walsh, editors. Raven Press. New York, New York, USA. 1285-1309.

2. Flemström, G., and Isenberg, J.I. 2001. Gastroduodenal mucosal alkaline secretion and mucosal protection. News Physiol. Sci. 16:23-28.

3. Flemström, G., and Kivilaakso, E. 1983. Demonstration of a pH-gradient at the luminal surface of rat duodenum and its dependence on mucosal alkaline secretion. Gastroenterology. 84:787-794.

4. Paimela, H., Kiviluoto, T., Mustonen, H., Sipponen, P., and Kivilaakso, E. 1990. Tolerance of rat duodenum to luminal acid. Dig. Dis. Sci. 35:1244-1248.

5. Larson, G.M., Jedstedt, G., Nylander, O., and Flemström, G. 1996. Intracerebral adrenoceptor agonists influence rat duodenal mucosal bicarbonate secretion. Am. J. Physiol. 271:G831-G840.

6. Flemström, G., and Jedstedt, G. 1989. Stimulation of duodenal mucosal bicarbonate secretion in the rat by brain peptides. Gastroenterology. 97:412-420.

7. Lenz, H.J., Vale, W.W., and Rivier, J.E. 1989. TRH-induced vagal stimulation of duodenal $\mathrm{HCO}_{3}^{-}$mediated by VIP and muscarinic pathways. Am. J. Physiol. 257:G677-G682.

8. Lenz, H.J. 1989. Regulation of duodenal bicarbonate secretion during stress by corticotropin-releasing factor and beta-endorphin. Proc. Natl. Acad. Sci. USA. 86:1417-1420.

9. Säfsten, B., Jedstedt, G., and Flemström, G. 1991. Effects of diazepam and Ro 15-1788 on duodenal bicarbonate secretion in the rat. Gastroenterology. 101:1031-1038.

10. Takeuchi, K., Yagi, K., Kato, S., and Ukawa., H. 1997. Roles of prostaglandin E-receptor subtypes in gastric and duodenal bicarbonate secretion in rats. Gastroenterology. 113:1553-1559. 
11. Vanecek, J. 1998. Cellular mechanisms of melatonin action. Physiol. Rev. 78:687-721.

12. Sugden, D. 2000. Melatonin receptors. Tocris Report. 14:1-3.

13. Benouali-Pellissier, S. 1994. Melatonin is involved in cholecystokinininduced changes of ileal motility in rats. J. Pineal. Res. 17:79-85.

14. Larsen, K.R., Moore, J.G., and Dayton, M.T. 1991. Circadian rhythms of acid and bicarbonate efflux in fasting rat stomach. Am. J. Physiol. 260:G610-G614.

15. Raikhlin, N.T., and Kvetnoy, I.M. 1976. Melatonin and enterochromaffine cells. Acta. Histochem. 55:19-24.

16. Lee, P.P., and Pang, S.F. 1993. Melatonin and its receptors in the gastrointestinal tract. Biol. Signals 2:181-193.

17. Bubenik, G.A. 1980. Localization of melatonin in the digestive tract of the rat. Effect of maturation, diurnal variation, melatonin treatment and pinealectomy. Horm. Res. 12:313-323.

18. Sababi, M., and Nylander, O. 1994. Elevation of intraluminal pressure and cyclooxygenase inhibitors increases duodenal alkaline secretion. Am J. Physiol. 266:G22-G30.

19. Hoffman, R.A., and Reiter, R.J. 1965. Rapid pinealectomy in hamsters and other small rodents. Anat. Rec. 153:19-21.

20. Takeuchi, K., Takehara, K., Kato, S., and Yagi, K. 1997. PACAPs stimulate duodenal bicarbonate secretion at PACAP receptors in the rat. Am. J. Physiol. 272:G646-G653.

21. Gibinski, K. 1987. A review of seasonal periodicity in peptic ulcer disease. Chronobiol. Int. 4:91-99.

22. Scheving, L.A. 2000. Biological clocks and the digestive system. Gastroenterology. 119:536-549.

23. Huether, G., Poeggeler, B., Reimer, A., and George, A. 1992. Effect of tryptophan administration on circulating melatonin levels in chicks and rats: evidence for stimulation of melatonin synthesis and release in the gastrointestinal tract. Life Sci. 51:945-953.

24. Lundberg, J.M., et al. 1978. Ultrastructural evidence for an innervation of epithelial enterochromaffine cells in the guinea pig duodenum. Acta Physiol. Scand. 104:3-12.

25. Joo, N.S., London, R.M., Kim, H.D., Forte, L.R., and Clarke, L.L. 1998. Regulation of intestinal $\mathrm{Cl}^{-}$and $\mathrm{HCO}_{3}{ }^{-}$secretion by uroguanylin. Am.J. Physiol. 274:G633-G644.

26. Sjöblom, M., Jedstedt, G., and Flemström, G. 2001. Effects of melatonin on duodenal enterocyte calcium signaling and bicarbonate secretion. Gastroenterology. 120:A312. (Abstr.)

27. Overstreet, D.H., Pucilowski, O., Retton, M.C., Delagrange, P., and Guardiola Lemaitre, B. 1998. Effects of melatonin receptor ligands on swim test immobility. Neuroreport. 9:249-253.

28. Wetterberg, L. 1999. Melatonin and clinical application. Reprod. Nutr. Dev. 39:367-382.

29. Messmer, B., Zimmerman, F.G., and Lenz, H.J. 1993. Regulation of exocrine pancreatic secretion by cerebral TRH and CGRP: role of VIP, muscarinic, and adrenergic pathways. Am. J. Physiol. 264:G237-G242.

30. Weijnen, J.A., et al. 2000. Main trajectories of nerves that traverse and surround the tympanic cavity in the rat. J. Anat. 197:247-262.

31. Yang, M., Zhao, X., and Miselis, R.R. 1999. The origin of catecholaminergic nerve fibers in the subdiaphragmatic vagus nerve of the rat. J. Auton. Nerv. Syst. 76:108-1217.

32. Merle, A., et al. 2000. Effect of melatonin on motility pattern of small intestine in rats and its inhibition by melatonin receptor antagonist $\mathrm{S}$ 22153. J. Pineal. Res. 29:116-124. 